Yoshinori Murakami • Hiroshi Uejima • Hiroshi Fukuhara

Tomoko Maruyama • Mitsuo Oshimura • Takao Sekiya

\title{
Construction of human-rodent hybrid cells containing single transferable fragments of human chromosome 10p
}

\begin{abstract}
The introduction of chromosome 10p into human glioblastoma or prostate cancer cells has been demonstrated to suppress their malignant phenotype, suggesting the presence of glioma or prostate tumor suppressor genes on $10 \mathrm{p}$. As a resource for the fine mapping of these genes, a series of human-rodent hybrid cell lines containing single transferable fragments (STFs) of 10p were constructed. Normal chromosome 10 tagged with a neomycinresistance gene on its short arm was fragmented by gamma-irradiation of 5-10 krad, transferred into mouse L cells or Chinese hamster ovary cells by microcell-mediated chromosome transfer (MMCT), and then selected against G418. Thirty-three independent rodent-human hybrids carrying various-sized STFs were obtained. Polymerase chain reaction (PCR)-based genotyping revealed that these STFs contained the whole, or portions, of a $43-\mathrm{cM}$ region on 10p14-pter and could be defined by 19 sequence-tagged-site (STS) markers. Using this panel of hybrids as donors for further MMCT, genes on the refined fragments could be transferred into other cells. This hybrid panel would therefore be a useful resource for the fine mapping of the genes on 10p14-pter to segments of about $2.4 \mathrm{cM}$ by functional complementation.
\end{abstract}

Key words Microcell-mediated chromosome transfer . Chromosome 10p · Rodent-human hybrid - Single transferable fragment $\cdot$ Tumor suppressor gene

Y. Murakami $(\bowtie) \cdot$ H. Fukuhara $\cdot$ T. Maruyama $\cdot$ T. Sekiya Tumor Suppression and Functional Genomics Project, National Cancer Center Research Institute, 5-1-1 Tsukiji, Chuo-ku, Tokyo 104-0045, Japan

Tel. +81-3-3542-2511, ext 4806; Fax +81-3-5565-9535

e-mail: ymurakam@gan2.ncc.go.jp

H. Uejima $\cdot$ M. Oshimura

School of Life Science, Faculty of Medicine, Tottori University,

Tottori, Japan

\section{Introduction}

Genetic complementation studies performed by microcellmediated chromosome transfer (MMCT) can provide information on the chromosomal location of the genes responsible for a specific cells phenotype, including that of cancer (Kozak et al. 1979). Fine mapping of the genes, however, cannot be performed by the transfer of whole or large portions of chromosomes. To overcome this problem, fragmentation of chromosomes by gamma-irradiation coupled with MMCT has been developed, and the loci for tumor suppressor genes in human rhabdomyosarcomas and prostate cancers were defined on chromosomal fragments 11p15 and 17q12-q22, respectively (Koi et al. 1993, Murakami et al. 1995). Several studies, including ours, have demonstrated that the transfer of normal human chromosome $10 \mathrm{p}$ into human glioblastoma or prostate cancer cell lines suppressed their malignant phenotype, suggesting the presence of tumor suppressor genes on chromosome 10p (Steck et al. 1995, Sanchez et al. 1996, Murakami et al. 1996, Kon et al. 1998).

\section{Materials methods results, and discussion}

For the fine mapping of the genes on $10 p$ by functional complementation, we constructed a panel of human-rodent hybrid cells carrying single transferable fragments (STFs) derived from various portions of human chromosome $10 \mathrm{p}$ by a combination of gamma-irradiation and MMCT.

The mouse-human microcell hybrid HA(10)A (Coriell Cell Repositories, Camden, NJ, USA) carries a human chromosome 10 tagged with a neomycin-resistance $\left(\right.$ neo $\left.{ }^{\mathrm{R}}\right)$ gene on its short arm (Pershouse et al. 1993). HA(10)A was treated with colcemid (Sigma, St. Louis, MO, USA) at a concentration of $0.06 \mu \mathrm{g} / \mathrm{ml}$ for $48 \mathrm{~h}$. Microcells were produced following centrifugation of micronucleated cells in the presence of $10 \mu \mathrm{g} / \mathrm{ml}$ cytochalasin B (Sigma) for enucleation, fragmented by gamma-irradiation of 


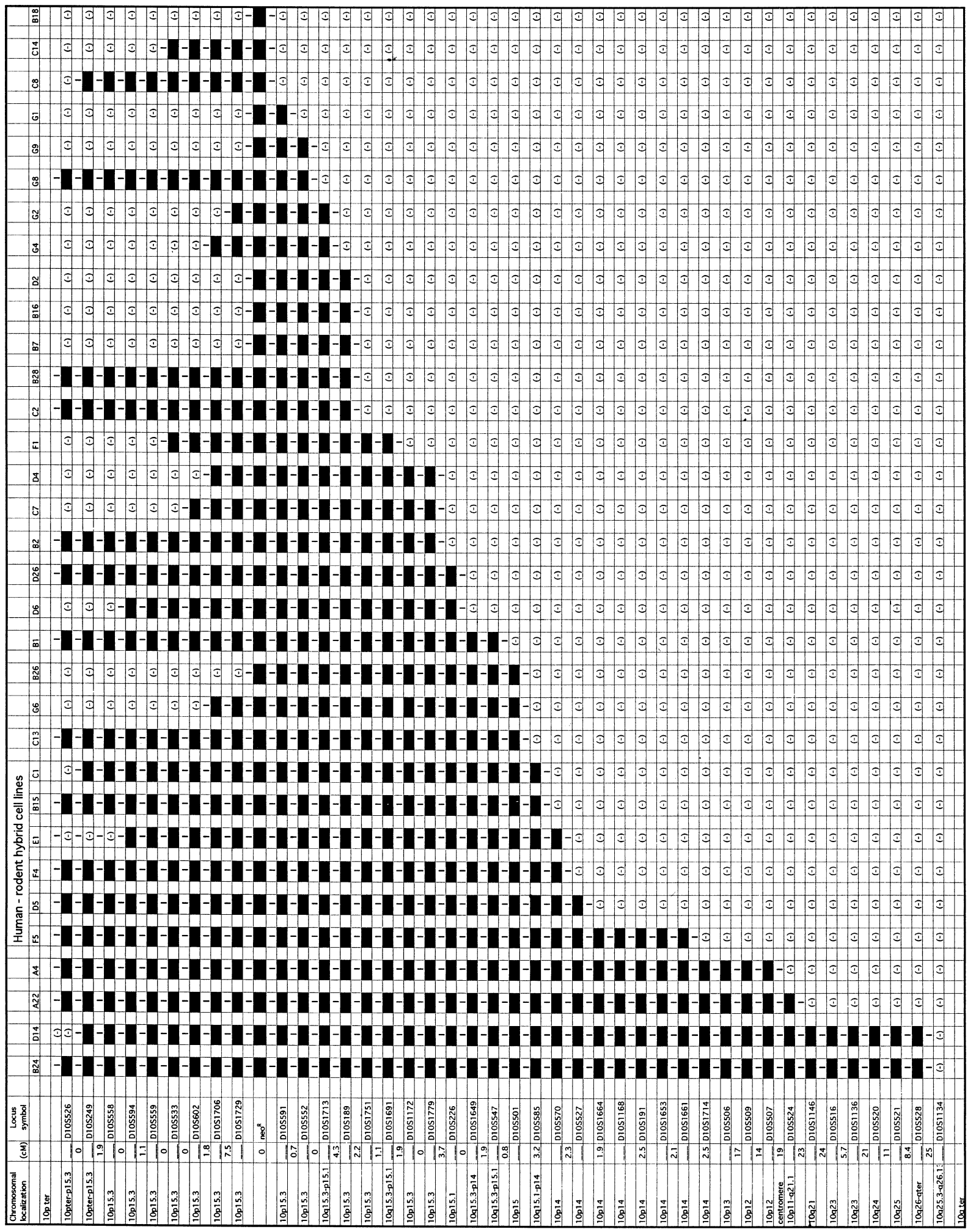

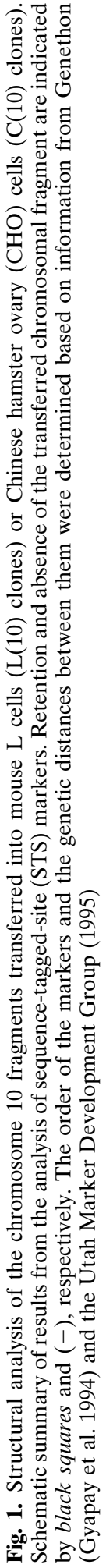


5-10 krad, and fused with mouse L cells with polyethylene glycol (PEG1500; Boehringer Mannheim, Mannheim, Germany).

Thirty-nine neomycin-resistant colonies were obtained from three independent transfer experiments. Transferred and retained chromosomal regions in each hybrid cell were determined by polymerase chain reaction (PCR)-based analyses of DNA, using 33 polymorphic microsatellite markers on the short arm and 8 markers on the long arm of chromosome 10. Two hybrids, L(10)A4 and L(10)A22, showed retention of continuous fragments of chromosome 10, as summarized in Fig. 1, while the other 37 hybrids retained more than two fragments of chromosome 10 (data not shown). These results were directly confirmed by fluorescence in situ hybridization (FISH) analysis of the hybrids, using human CotI DNA as a probe, as described previously (Kugoh et al. 1995). Representative results are shown in Fig. 2. L(10)A22 cells retained only one human chromosomal fragment (Fig. 2a), while L(10)A16 cells car- ried at least three discontinuous human fragments, either as an independent chromosome or translocated to chromosome of mouse (Fig. 2b).

Then, in order to obtain human-rodent hybrids containing single transferable fragments (STFs) of chromosome 10, 37 hybrids carrying multiple fragments of chromosome 10 obtained in the first-round MMCT were pooled and used as donor cells for the second-round MMCT. Only the chromosomal fragments tagged with the $n e o^{\mathrm{R}}$ gene were expected to be transferred. In this instance, Chinese hamster ovary (CHO) cells were used as recipients, and fusion was performed without irradiation. Thirty-seven clones were obtained by selection against G418 after eight independent transfer experiments. PCR-based analyses revealed that a total of 31 hybrid cells carried single continuous fragments of chromosome 10 (Fig. 1). FISH analysis confirmed that these hybrids retained single chromosomal fragments, either as an independent chromosome (Fig. 2c) or translocated to chromosome of hamster (Fig. 2d).
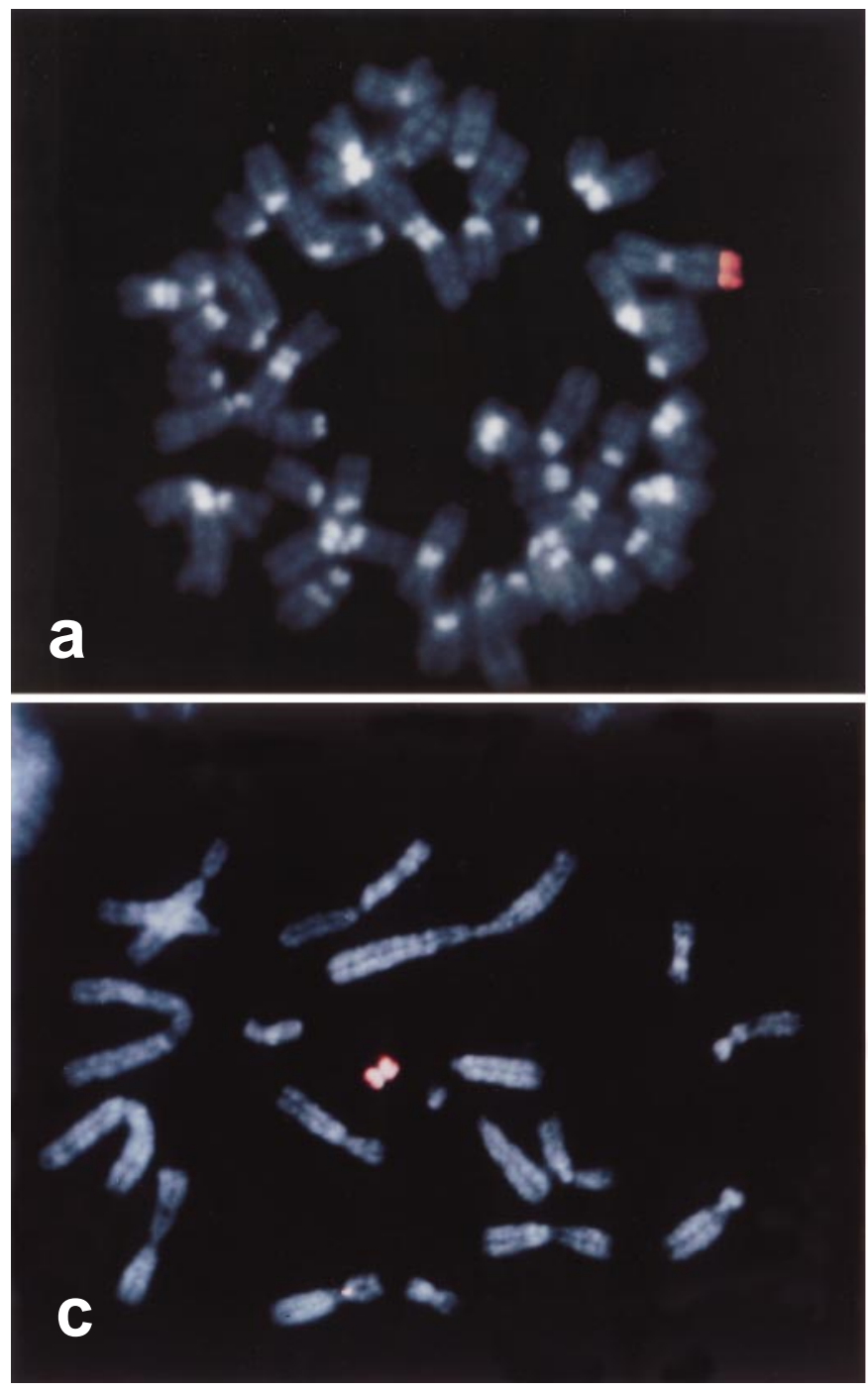

Fig. 2a-d. Fluorescence in situ hybridization (FISH) analysis of the human chromosome 10 fragments transferred into mouse $\mathrm{L}$ or $\mathrm{CHO}$ cells. Human CotI DNA was used as a probe, as described previously
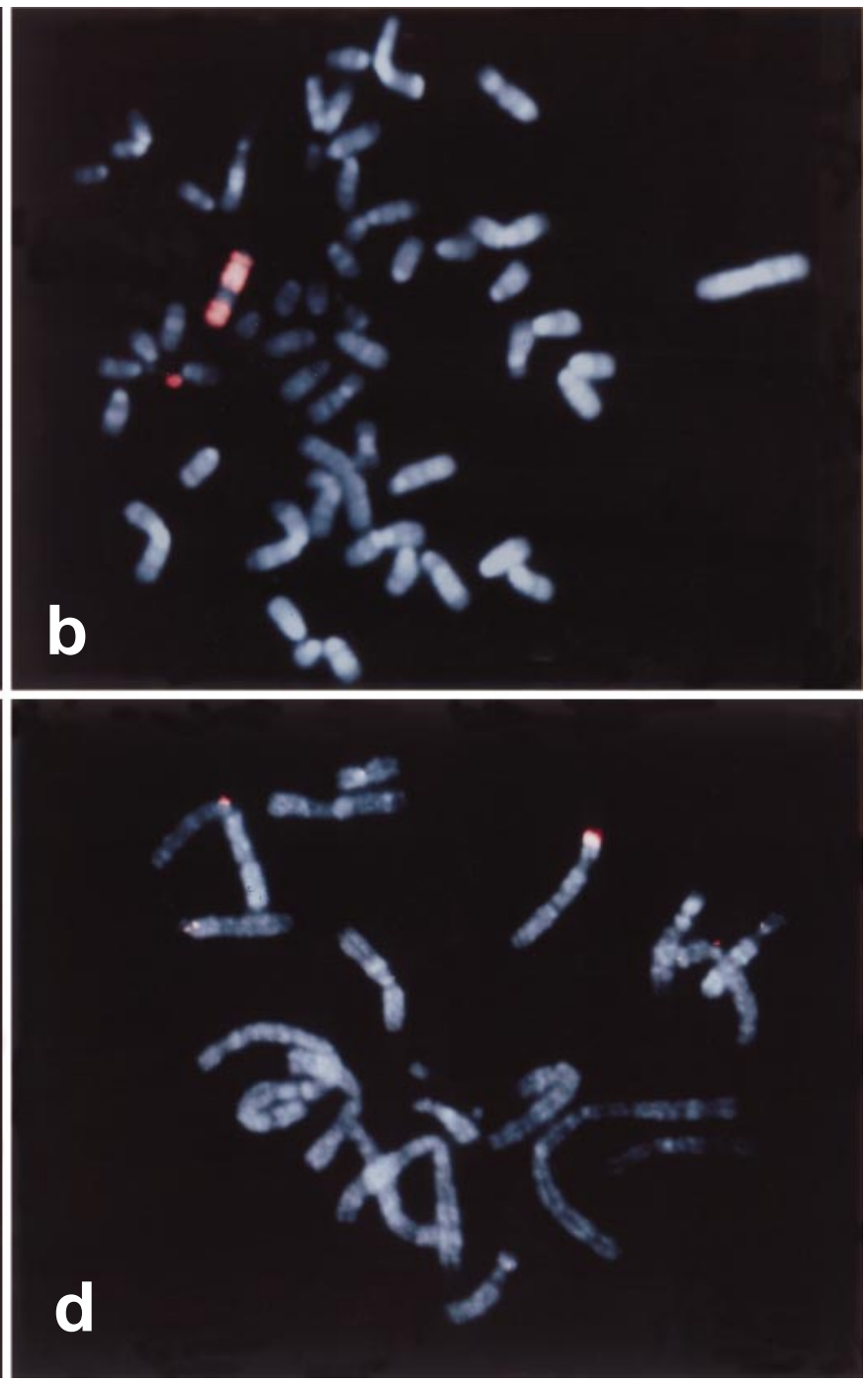

(Kugoh et al. 1995). Analysis of human-mouse hybrids, L(10)A22 (a) and L(10)A16 (b) and human-hamster hybrids, C(10)C7 (c) and $\mathrm{C}(10) \mathrm{C} 2(\mathbf{d})$ 
The results of a genotyping study in 2 human-mouse and 31 human-hamster hybrids are summarized in Fig. 1. Because the fragment flanked by the STS marker, D10S591, was commonly retained in all but one hybrid, B18, the $n e o^{\mathrm{R}}$ gene in HA(10)A cells appeared to be integrated adjacent to this region. As shown in Fig. 1, a total of 33 independent hybrids contained STFs covering the whole or a portion of 10p14-pter, with a genetic distance of $43 \mathrm{cM}$. Because these STFs were defined by 19 STS markers, genes on 10p14-pter could be mapped to segments of an average $2.4 \mathrm{cM}$ by genetic complementation study through MMCT.

Using these hybrids as donor cells for MMCT, we have transferred several structurally refined STFs on 10p14-pter into PPC-1 cells in order to narrow down the region harboring a prostate tumor suppressor gene (data not shown). Koi et al. (1993) had previously reported a similar panel of hybrid cells containing various STFs of human 11p. The hybrids constructed in the present study could be distributed on request as resources for the structural and functional analysis of human chromosome 10p.

Acknowledgments This work was supported by a Grant-in-Aid for Special Projects for Cancer Research from the Ministry of Education, Science, Sports, and Culture of Japan and by a Grant-in Aid for the Second Comprehensive 10-Year Strategy for Cancer Control from the Ministry of Health and Welfare of Japan. H.F. is a recipient of Research Resident Fellowships from the Foundation for the Promotion of Cancer Research of Japan.

\section{References}

Gyapay G, Morissette J, Vignal A, Dib C, Fizames C, Millasseau P, Marc S, Bernardi G, Lathrop M, Weissenbach J (1994) The 1993-94 Genethon human genetic linkage map. Nat Genet 7: 246-339
Koi M, Johnson LA, Kalikin LM, Little PFR, Nakamura Y, Feinberg AP (1993) Tumor cell growth arrest caused by subchromosomal transferable DNA fragments from chromosome 11. Science 260: 361-364

Kon H, Sonoda Y, Kumabe T, Yoshimoto T, Sekiya T, Murakami Y (1998) Structural and functional evidence for the presence of tumor suppressor genes on the short arm of chromosome 10 in human gliomas. Oncogene 16: 257-263

Kozak CA, Fournier RE, Leinwand LA, Ruddle FH (1979) Assignment of the gene governing cellular ouabain resistance to Mus musculus chromosome 3 using human/mouse microcell hybrids. Biochem Genet 17: 23-34

Kugoh H, Nakagawa Y, Mitsuya K, Mita T, Suzuki M, Suzuki N, Uejima H, Yuasa Y, Oshimura M (1995) Isolation and mapping of 186 new DNA markers on human chromosome 1. Genomics 27: 207210

Murakami YS, Brothman AR, Leach RJ, White RL (1995) Suppression of malignant phenotype in a human prostate cancer cell line by fragments of normal chromosomal region 17q. Cancer Res 55: 33893394

Murakami YS, Brothman AR, Leach RJ, White RL (1996) Suppression of the malignant phenotype of a human prostate cancer cell line PPC-1 by introduction of mormal human chromosome fragment 10. Cancer Res 56: 2157-2160

Pershouse MA, Stubblefield E, Hadi A, Killary AM, Yung WK, Steck PA (1993) Analysis of the functional role of chromosome 10 loss in human glioblastomas. Cancer Res 53: 5043-5050

Sanchez Y, Lovell M, Marin MC, Wong PE, Wolf-Ledbetter ME, McDonnell TJ, Killary AM (1996) Tumor suppression and apoptosis of human prostate carcinoma mediated by a genetic locus within human chromosome 10pter-q11. Proc Natl Acad Sci USA 93: 25512556

Steck PA, Ligon AH, Cheong P, Yung WK, Pershouse MA (1995) Two tumor suppressive loci on chromosome 10 involved in human glioblastomas. Genes Chromosom Cancer 12: 255-261

Utah Marker Development Group (1995) A collection of ordered tetranucleotide repeat markers from the human genome. Am J Hum Genet 57: 619-628 